symptom severity. Fever reappeared approximately at 2 weeks after admission. He presented neurologic deterioration with focal seizures, choreiform movements, facial dyskinesia, psychomotor regression to the age of 2 months. These symptoms were suggestive of an autoimmune encephalitis. NMDAR antibodies were detected in CSF. Recurrent HSV encephalitis was excluded. Steroids and Intravenous Immunoglobulins were associated to the therapy scheme. The patient recovered slowly and partially but remained with neurological sequelae.

Discussion Our case exemplifies an anti NMDAR encephalitis which developed in the convalescence phase of a viral infection. HSV-1 infection may be a trigger for anti-NMDAR encephalitis. Autoimmune encephalitis after viral infection is important to be recognized early as patients can receive treatment with steroids and immunosuppressants in order to improve their outcome.

\section{GP46 CONGENITAL HYPERINSULINISM: IMPORTANCE OF EARLY DIAGNOSIS BY GENETICS \& F-DOPA SCANNING FOR OPTIMAL MANAGEMENT: 2 SEPARATE CASE REPORTS}

${ }^{1}$ Pankaj Agrawal ${ }^{*},{ }^{1}$ Claire Reynolds, ${ }^{1}$ Beth Gordon, ${ }^{1}$ Elena Hennessy, ${ }^{2}$ Raja Padidela, ${ }^{1}$ Stephen MP O'Riordan. 'Cork University Hospital, Cork, Ireland; ${ }^{2}$ Royal Manchester Children Hospital, Manchester, UK

10.1136/archdischild-2019-epa.112

Background Congenital hyperinsulinism (CHI) is a rare inherited disease ( 1 in 50,000 newborns), that can be diffuse or focal. Mutations in ABCC8 gene are the most common cause. Advances in molecular genetics, imaging techniques (18FDOPA-PET-CT) and surgery have radically improved the outcome

Objective To report two cases of infants with $\mathrm{CHI}$ and highlight how early genetic results aided medical and surgical management

Case 1 A $5.68 \mathrm{~kg}$, baby boy born at term via normal delivery had hypoglycaemia (blood glucose (BG) $0.8 \mathrm{mmol} / \mathrm{L}$ ) at 2 hours of life. He required a glucose load of $20.2 \mathrm{mg} / \mathrm{kg} / \mathrm{min}$, $25 \%$ dextrose and fluid volume $200 \mathrm{ml} / \mathrm{kg} /$ day. At BG $<2.6$ $\mathrm{mmol} / \mathrm{L}$ Insulin was $180 \mathrm{pmol} / \mathrm{L}(<14 \mathrm{pmol} / \mathrm{L})$ in the absence of ketosis. He was unresponsive to maximum dose of Chlorthiazide \& Diazoxide (20 mg/kg/day) and Octreotide $10 \mathrm{mcg} /$ $\mathrm{kg} /$ day. He had difficult IV access and required a PICC line. Subsequently he was commenced on glucagon infusion prior to transfer to The Northern Congenital Hyperinsulinism Service (NORCHI), U.K

Case 2 A $4 \mathrm{~kg}$, term, male baby, forceps delivery was admitted to NICU on day 1, with hypoglycaemia (blood glucose (BG) of $1.4 \mathrm{mmol} / \mathrm{L})$. Despite increasing glucose load of $>$ $18 \mathrm{mg} / \mathrm{kg} / \mathrm{min}$, Dextrose $20 \%$ and fluid volume $180 \mathrm{ml} / \mathrm{kg} /$ day, he continued to be hypoglycaemic. At BG of 0.9 $\mathrm{mmol} / \mathrm{L}$ Insulin was $170 \mathrm{pmol} / \mathrm{L}(<14 \mathrm{pmol} / \mathrm{L})$ without ketosis. He was commenced on Diazoxide \& Chlorthiazide but considered unresponsive, due to ongoing hypoglycaemia. Furthermore, he received a glucagon infusion $12.5 \mathrm{mcg} / \mathrm{kg} / \mathrm{hr}$ \& transferred to NORCHI where his Diazoxide was stopped while Glucagon \& Octreotide continued. In both cases, early genetic samples were sent from CUH. Thus, by the time they reached NORCHI, genetic results were available: both cases were heterozygous paternally inherited mutation in ABCC8 gene. F-DOPA scanning revealed a focal lesion in the body and head of pancreas for the first and second case respectively. A laparoscopic focal pancreatic lesionectomy was performed in both cases. The post-operative period for the first case was uneventful with no hypoglycaemias, discontinuation of Glucagon \& Octreotide providing complete cure without medications. Post-surgery the second case required subcutaneous Octreotide $10 \mathrm{mcg} / \mathrm{kg} /$ day in four divided doses, due to residual hyperinsulinemic tissue. At three years of age repeat F-DOPA scan revealed no residual lesion. Subsequently, he was weaned off Octreotide without any further hypoglycaemia.

Conclusion In both cases early detection of CHI with early genetic testing, F-DOPA scanning and collaboration with centres of excellence like NORCHI, all optimised the care \& appropriate management.

\section{GP47 A NOVEL MUTATION IN AUTOSOMAL DOMINANT SPASTIC PARAPLEGIA TYPE 4}

Jayasree Kutty*. Department of Community Paediatrics, Omagh Hospital and Primary Care Complex, Omagh, UK

\subsection{6/archdischild-2019-epa.113}

Background Hereditary Spastic Paraplegia (HSP) is a rare group of diseases characterized by slowly progressive degeneration of the corticospinal tracts. It can present at any age with varying degrees of lower limb spasticity and weakness. HSP syndromes are classified as 'complicated' when associated with other neurologic features such as muscle atrophy, ataxia or cognitive impairment. Mode of inheritance can be autosomal dominant, recessive or $\times$ linked and more than 80 genetic types of HSP have been identified. Usually diagnosis is delayed due to its low prevalence and variable clinical phenotypes.

Method A 3 year old female child, born to non-consanguineous parents presented at 17 months with delayed walking. She was walking with both hands held and her gait pattern looked abnormal. She had had a previous normal hip ultrasound examination at 6 weeks of age as there was a history of breech presentation. Hip X-rays later ruled out developmental dysplasia of hips. She attended physiotherapy and at two years of age was not still walking independently. She was a term infant with unremarkable perinatal history. Her father and a paternal cousin had a diagnosis of 'cerebral palsy'. An older male sibling is asymptomatic. Examination revealed weight bearing on her forefeet with lower limbs turning to internal rotation suggestive of a diplegic gait. There was mildly increased tone in her lower limbs with bilateral brisk reflexes and extensor plantars. Upper limb examination was normal. Developmental examination was age appropriate. While she had normal hip x-rays and MRI scan of the brain, the family history prompted further investigations looking for a familial cause for her clinical picture.

Results Genetic panel for HSP identified a novel heterozygous mutation in exon 12 of the SPAST c.1478A $>$ T, p (Asp493Val) gene consistent with a diagnosis of autosomal dominant spastic paraplegia type 4 . This is considered as an 'uncomplicated' HSP where symptoms might not progress over many years. The same genetic mutation was confirmed in her father too.

Conclusion The clinical findings and family history led to targeted genetic testing, subsequent early diagnosis and appropriate genetic counselling of family members. 